\title{
Internships in Kinesiology: Reconsidering best practices
}

\author{
Mark Urtel, Indiana University Purdue University Indianapolis \\ Sara F. Michaliszyn, Youngstown State University \\ Craig Stiemsma, Dordt College
}

\begin{abstract}
Mark Urtel is the Chair of the Department of Kinesiology at Indiana University Purdue University Indianapolis. Sara Michaliszyn is Chair of the Department of Kinesiology and Sport Science at Youngstown State University, and Craig Stiemsma is Chair of the Department of Health and Human Performance at Dordt College.

Correspondence concerning this article should be addressed to Mark Urtel, IUPUI-PE 267, 901 West New York Street, Indianapolis, IN 46202. Contact: murtel1@iupui.edu
\end{abstract}

\begin{abstract}
The purpose of this paper is to summarize the 2018 American Kinesiology Association (AKA) pre-workshop on best practices in internships. This pre-workshop contained 2 keynote speakers, 5 ignite sessions, and 6 round-table discussions looking at the status of internships in departments of kinesiology, nationally. It is clear kinesiology does not have a common practice for implementing internships. Given the many variables in respect to offering an internship, such as: curricular mandates, faculty workload policy, community partner availability, program outcomes, student learning objectives, and assessment tools this is not surprising. Perhaps we should rethink the notion that there is a set of best practices that guide internship development and consider the possibility that internships will look different at various institutions for valid reasons.
\end{abstract}

Keywords: high impact practices, sub-disciplines, assessment, student learning outcomes

This is the author's manuscript of the article published in final edited form as:

Urtel, M., Michaliszyn, S. F., \& Stiemsma, C. (2018). Internships in Kinesiology: Reconsidering Best Practices. Kinesiology Review, 7(4), 350-357. https://doi.org/10.1123/kr.2018-0036 
Internships in Kinesiology: Reconsidering best practices

Internships in higher education are not a new practice. In fact, it is generally noted that the first formal internship program occurred in 1889 at Johns Hopkins Medical School (Wentz \& Ford, 1984). Prior to this, medical school faculty were developing ways for medical "apprentices" to acquire more practice. Eventually after years of refinement, the internship came to be. This iterative process was neither orderly nor driven by particular learning outcomes; rather, it evolved to address the observation that the "apprentices" simply need more structured and guided practice (Wentz \& Ford, 1984). When it comes to internships in kinesiology, one could argue we have mirrored this medical school model.

Outside of student teaching, it is not exactly clear when internships started within kinesiology. The most accessible references came from the literature in the 1980's and 1990's. However, apprenticeships in teacher preparation programs occurred in the last quarter of the $19^{\text {th }}$ Century (Labaree, 2008). As a result, the development of focused teacher preparation programs (termed Normal colleges) started at about this time with the Normal College of the American Gymnastics Union formally being birthed in 1866 . The Normal College of the American Gymnastics Union was the first official and formal teacher training program for those focused on teaching Physical Education (Rinsch, 1966). Taken together, one can surmise that apprenticeship training, which we now know as both field experience learning and student teaching, first started around the end of the $19^{\text {th }}$ and beginning of the $20^{\text {th }}$ Century.

It is intriguing to hypothesize that non-teaching-based kinesiology internships grew largely out of the physical education pedagogy student teaching framework. Concurrently, kinesiology faculty tended to emulate what colleagues in business and other academic disciplines in higher education were doing as it pertained to internship planning, preparation, and 
implementation. This real-life off-campus experience, under the mentorship of an experienced practitioner proved invaluable and led to a broader conversation within kinesiology on how to integrate internships in other plans of study.

Based on the conversations at the American Kinesiology Association (AKA) 2018 preworkshop, there is a lack of common practice in undergraduate kinesiology internship requirements. This variability is completely understandable when one reflects upon the numerous sub-disciplines of kinesiology including: Sport history, exercise science, sport and exercise psychology, motor development, motor learning, exercise physiology, sports medicine, sport biomechanics, sport philosophy, sport sociology, physical education pedagogy, adapted physical activity, and sport management. All these sub-disciplines have varied foci which lead to different learning objectives and curricular expectations that may or may not need to address state-level competencies and/or national accreditation requirements.

In addition to the varying emphases within kinesiology, it should be noted that kinesiology as an academic discipline is housed in different schools/colleges and different departments - even within the same university. For example, one of the authors works for Indiana University which contains multiple campuses, located around the state. The Bloomington campus houses kinesiology within the School of Public Health. Within the Indianapolis campus, it is housed in the School of Health and Human Sciences. Other college/school names may include: Community Health, Nursing and Allied Health, Education, Human Ecology, Health Science, Human Performance, or Health and Human Development, just to name a few. These different academic locations may further influence a curriculum as well as the overall and individual internship requirements by way of college/school specific budget models, faculty workload policies, and curriculum guidelines, just to name a few influences. 
Therefore, it is not surprising that the internship experience in kinesiology appears more like a mosaic nationally. This also helps explain why there is a dearth of universal expectations. In a sense, each academic unit needs to be sensitive to their academic home, budget model, community they are situated in, and various faculty and academic policies to develop the best internship program they can, specific to the resources they have access to.

In sum, it is our intention that this paper will contextually frame the status of internships within kinesiology today and support our respective efforts on achieving best practices within our varied academic environments.

\section{Purpose of an internship}

The purpose of the internship is to offer apprentices more practice time in an applied setting away from the classroom. Based on the success of this model it has become quite clear how significant internships are connected to the undergraduate, graduate, and professional program experience. The National Association of Colleges and Employers (2013) highlight three important outcomes of an internship program: the chance to apply academic training in a realworld environment, to obtain transferable skills, and to receive feedback. Stack and Fede (2017) discuss this a bit further in relation to transferable skills as they specify the acquisition of softskills (e.g. verbal communication, prioritization of work, and obtaining/processing information); which while highly valued tend to be overlooked in a typical curriculum that is exclusively course-based. In fact, Morrisey, Beckett, Sherman, and Leininger (2017) point out that there is conclusive societal thought that students should graduate from programs being able to use the knowledge and skills gained from programs and not simply possess them; additionally, they should do so for the public good. Done properly, internships tend to meet both expectations. 
In addition, internships are considered a high impact practice (HIP) regardless of major or discipline and are positively associated with student learning and retention and typically require out-of-classroom time, meaningful interaction with a faculty member, collaboration with diverse groups, along with frequent feedback (Kuh, O’Donnell, \& Schneider, 2017). When done successfully, a HIP is unequivocally beneficial to students. Collectively, it becomes clear that kinesiology programs that include internship components in their degree programs are setting their students up for success as they transition into entry-level positions. It also allows students to embark with confidence on their next steps in either graduate or professional school programs. This notion is supported by Paternostro-Bayles (2009) who comments on the vibrancy of the exercise science profession, noting increases in employment in fitness and exercise jobs based on the Bureau of Labor statistics (projections from 2006-2016).

Additionally, a survey by the IDEA Health and Fitness Association (Ryan, 2005) demonstrates the future need for more people in kinesiology related occupations. Both findings reinforce the idea that graduates from programs that prepare students for these professions should offer appropriate internships prior to graduation. This will allow these students to apply learned skills/knowledge, exhibit mature soft-skills, and be trainable to a future employer. As an added benefit, Paternostro-Bayles (2009) also reminds us that kinesiology and exercise science related internships may have value in helping a student decide what specific career opportunities mesh with their specific interests.

Bulger (2006) shares four lasting benefits to the intern's employer: (a) chance to infuse new methods, concepts and ideas directly from institutions of higher learning (b) to recruit and observe new talent (c) to train new prospects at a low cost and (d) to improve undergraduate 
educational preparation via feedback to the institution. In effect, an internship is usually a winwin between student and placement site.

\section{General internship framework}

The pre-workshop revealed the interesting and vast landscape of internships in our discipline. Among the many topics introduced and shared included: curricular placement, prerequisites, time requirements, credit hour value, departmental oversight, legal agreements, faculty oversight, evaluation and assessment techniques, placement site compensation, placement site selection, placement site orientation, and exit interviews/de-briefing formats. Two major elements of the internship stood out during the session: contrasting credit hour and time requirements of an internship in kinesiology. Per some pre-workshop participants, their kinesiology internship goes a full academic year and constitutes 10 or more credit hours within the curriculum. At other institutions the internship goes one semester and takes 3-9 credit hours. We noted that at some institutions the internship is a 1-3 credit hour course requiring minimal hours per week, and yet, some kinesiology programs do not contain an internship at all. Particular to the authors of this article, at Indiana University Purdue University Indianapolis (IUPUI), the kinesiology internship is typically one semester in duration (or one summer; over both sessions) and equates to 7-credit hours. At Youngstown State University, the internship also lasts one semester (or one full summer) and equates to 8-credit hours. At Dordt College, the internship is a variable credit experience, with a minimum being 3-credit hours and the maximum being 9-credit hours; with the duration relative to the credit hour value.

Upon hearing this range, initially our collective thoughts were focused on how ideal and even advantageous it would be to have national standard requirements for how to offer a kinesiology internship. However, after further dialogue with colleagues from disparate 
institutions in dissimilar areas of the country, we quickly learned that a best practice for someone in a metropolitan Carnegie R1 institution with a kinesiology focus toward exercise science, preprofessional training may be far different from someone at a small, private, rurally situated institute focused on athletic training or teacher preparation. Again, during the roundtable conversations with various colleagues who oversee or work within their internship program we realized how unique each of our situations were. More specifically, depending on how large each program was (enrolled students), how many faculty full-time equivalent hours (FTE) were attributed to the kinesiology program, what budget model their unit operated under, what their faculty workload policies looked like, and the type of community they were located in greatly impacted how their internship program was structured. At this point, when we debriefed from the roundtables, we pivoted from our initial thoughts and then considered whether or not there should be a "clearinghouse" of information and resources. This would allow kinesiology professionals interested in and/or tasked with internship expectations to find the best practices that work for them; based on the wide array of circumstances that impact curricular decisions.

This virtual clearinghouse would be for members to compare and use for their individual institutions against similar programs, nationally. Ideally, this would compress the time it may take them to land on the best format for internships given their location, curriculum, personnel, and institutional climate. The AKA may be an excellent home to take the lead in developing guidelines, both flexible and adaptable, that could be used on a national level for its very different member institutions. We hope to start this conversation here.

\section{Starting the conversation}

\section{Determining credit hours and curricular placement}


Students typically take core foundational, prerequisite, or even general studies courses related to science, psychology, social science, and arts and humanities early in their academic program. By the time students reach their junior or senior year, they have experienced 3 to 4 semesters of practice on these critical abilities as well as some core related courses to best prepare them for their internship. For this reason, placing the internship towards the end of the curriculum tends to be a common practice. In fact, for both IUPUI and Youngstown State University, the internship is a true capstone course taken at the end of a student's plan of study with only limited course work not completed. Specifically, for IUPUI up to a maximum of 6 credit hours can be remaining to complete the internship and for Youngstown State University all but 4 credit hours need to be completed; however, Dordt College does not consider the internship as a capstone experience because it can be taken as early as the sophomore year with the prerequisite of having just 24 college credits completed. These are just a few examples of the variability among kinesiology programs across the country.

Since a prime purpose of the internship is to acquire professional skills and career experience, interns typically spend a substantial amount of time at their internship site to allow them enough time to get into the norms of the position and complete deliverables that are valuable to both the student and the internship site. The duration of this experience is usually, but not always, linked to an academic semester or quarter. While the total amount of time may be dictated by school breaks. For example, summer sessions are typically shorter than fall and spring semester sessions. Some programs have chosen the practice of having a certain number of hours required for their internships to assure all students are receiving the same amount of time towards this experience regardless of when they take it and within the sub-discipline in which they are enrolled. In each of our institutions (IUPUI, Youngstown State University, and Dordt 
College), the duration of the internship is roughly 380,400 , or 360 hours, respectively, in a supervised setting. Based on the responses we gathered from pre-workshop participants, this range shifts from 80 to 440 hours, with some colleges and universities not requiring any required hours at all.

At times internship host sites also impact the duration of an internship experience. For instance, approximately $45 \%$ of 2000 employer representatives' report that they expect students to have between 6 to 12 months of full-time work experience prior to completing their degrees (Gardner, 2013). When asked what an appropriate length of time a student's internship should be these host sites found that 5\% indicated 2-4 months; 30\% indicated 3-4 months; $25 \%$ revealed 56 months, 9\% stated 7-10 months; and 30\% indicated that the experience had to last $\geq 12$ months (Gardner, 2013). It should be noted that these results are not limited to the discipline of kinesiology, where more research would be helpful in determining preferred kinesiology internship lengths. However, as Murray, Zakrajsek and Gearity (2013) indicate, the typical internship for strength and conditioning was sixteen weeks long.

\section{Determining internship content}

Prior to incorporating an internship into a curriculum, one may want to consider the following questions: (a) What do you want your students to demonstrate? And (b) what does the student want to learn?

The internship content is largely dependent on curricular requirements juxtaposed with student's future interest. As most internships are used as capstone projects, developing the internship to encompass the programs overall student learning outcomes is advantageous both from the student experiential learning perspective and for programmatic review. For example, at Youngstown State University the internship student learning outcomes parallel the American 
College of Sports Medicine's Certified Exercise Physiology (EP-C) job task analysis or the National Strength and Conditioning Associations Certified Strength and Conditioning Specialist (CSCS). On this point of curriculum mapping, Howard (2001) reminds faculty to ensure learning objectives of the internship are closely tied to the service experience of the host site, as well. If the internship site does not have their own student learning outcomes, providing cooperating facilities with a list of student learning outcomes they may choose to employ may help. This way the host site will have guidance on what to teach the intern while at the same time providing the intern with a clear set of expectations. Similarly, IUPUI does contain a general set of student learning outcomes mapped to the internship course, and these are guided, in part, by the American College of Sports Medicine (ACSM). However, at Dordt College there does not exist a set of established student learning outcomes mapped to a professional association for the internship. Instead, the student learning outcomes are established based on the placement site and course expectations. Table 1 demonstrates an example of student learning outcomes that could be provided to internship sites to choose from.

The pre-workshop revealed to us that there are many practices to foster the internship experience, content-wise, to match the student learning interests. For instance, IUPUI and Youngstown State University mandate that students independently research potential placement sites that align with their learning goals. As a result, the student will reach out to multiple potential host sites and identify reasons why this site matches their learning goals. Once established they are then asked to highlight the attributes of these possible sites to successfully host an intern (qualified personnel, mentoring experience, orientation process, etc.). Finally, these prospective sites are included on their application to the internship course. At this point, the internship faculty will determine which site is willing to host an intern and do so in a manner that 
supports their learning goals. It should be noted that each institution maintains a relatively active list of possible sites for students to explore.

This approach contrasts with other institutes at the pre-workshop. Some kinesiology internship programs find it logistically possible to have the program director (or similar position) find an internship site for each student. Other programs are structured so the internship director/coordinator works with each student early on, in a collaborative manner, to find an appropriate site. While other programs that do not have a director or coordinator invite students to seek guidance from any full-time faculty or mentor in finding a possible site that meets their learning goals.

When considering what the student would like to learn from the internship there are many approaches used to match those learning goals to a host-site. Since internships typically are intended to teach students to apply the knowledge, skills, and abilities taught in the classroom, finding alignment with a host-site is paramount for success. Furthermore, as internships are awarded academic credit they require faculty approval. The pre-workshop revealed the different ways faculty approval is granted.

\section{Common challenges}

The process of developing an internship component within the curriculum is both exhausting and exhilarating. While the establishment of goals, objectives, and outcomes of an internship satisfies the need for curricular mapping, it is the logistical plan that warrants much attention. It is beyond the scope of this paper to identify and address each possible challenge, concern, or issue with developing and delivering an internship. However, based on the preworkshop deliberations, we can address the most common talking points and areas of discussion. The identification of these issues reveals the discrepancy among the types of institutions and how 
that impacts "best practice". For instance, one program may view a specific vignette for internship inclusion as full of major challenge. However, for the same vignette an entirely different program may view it as full of opportunities.

\section{Internship placement site coordination/availability}

IUPUI has a faculty member dedicated to be the internship director who, among other things, ensures each student applying for an internship has met all course and grade point average pre-requisites linked to the internship. While Youngstown State University also requires completion of pre-requisite classes, with a minimum grade point average, this task is undertaken by the program director, not a dedicated internship director/coordinator. Dordt College, given the placement of the internship requirement in their plan of study and the size of the program, has a single faculty member coordinate these efforts as part of an individual's duties.

For many reasons, it may be difficult for an academic program to find appropriate sites to place their student interns. One limiting factor could be location. The discussions within the preworkshop tended to support the notion that if your institution happens to be in a more rural, or at least, in a less metropolitan setting there tends to be fewer options to place students. And this was echoed by our colleague from Dordt College; who resides in the $57^{\text {th }}$ largest city of Iowa - a small city, indeed. Not surprising, the reverse is true, in that institutions located in more populated regions tended to have more options. Youngstown State University, situated in the $9^{\text {th }}$ largest city in Ohio, has a solid balance of potential sites, relative to their program size. IUPUI is not only located in the largest city in Indiana, it is also identified as the $14^{\text {th }}$ largest city in the United States. There are considerably more internship sites than eligible students in this program.

Clearly, location is an impactful variable for each program yet in markedly different ways. For a program like Dordt College, it is important to not only prospect to find appropriate 
and meaningful internship sites, there is an even higher premium to maintain those site relationships, so the internship program can be sustained over time. Conversely, as is the case for IUPUI which again, is in a very metropolitan area, the reality is that there exist more placement sites than available students by a wide margin. While this may be considered a more favorable scenario, it is not without challenges. For example, if IUPUI turns down a request for sending an intern to a site, the site may stop asking for interns and try to find another institution or way to address their needs, outside of partnering with us. In effect, the program may be unintentionally removing a valued community partner from an inventory of approved sites if the program unable to send interns to those sites. The issue of internship host site availability is not new. In fact, Wolf and Svanum (1976) revealed this exact concern in a piece centered on internship site selection. They indicated that there aren't enough approved sites given the number of students needing the internship experience; and even identified that gap to be as large as $25 \%$.

\section{Internship supervision}

To some extent, it is evident that the type of program will define how the supervision of the internship experience is executed. In a perfect world, one would prefer to employ a director of internships. This person would be tasked with prospecting sites, approving sites, placing students, auditing students to be sure they were qualified and ready for the internship, hold student orientations prior to the internship beginning, make multiple site visits, maintain an internship website with information and FAQ's, keep a running and accurate list of approved sites, coordinate repeated evaluations, complete the final assessment, assess the student learning outcomes, facilitate exit interviews, and complete a $360^{\circ}$ evaluation of the process and product of the internship. Yet, given restricted budgets or faculty workload policies or a combination of both that we face in our unique situations, it may not be feasible to retain such a person. 
Therefore, a common approach is to afford interested and qualified faculty members course release to be the director or coordinator of internships, for the department. This may range from a 1 credit hour release per semester up to a 6 -credit hour release per semester. What makes this even more difficult to quantify in order to promote best practice, is the size (student enrollment) of an internship program. Furthermore, how active an internship program is across fall, spring, and summer sessions is another consideration.

IUPUI regularly has $40-50$ students per academic session in the internship program. This is a much different scale than Dordt College who may have 8-15 students in the internship program at any point in time. Some suggestions discussed in the pre-workshop centered on how to calibrate course release and other assistance provided to the person tasked with the internship based on the scope and scale of their program.

For a larger internship program like the IUPUI Department of Kinesiology, based on faculty workload policies, course release is afforded to the faculty member who directs the internship program and when the internship enrollment surpasses typical expectations a second faculty member ( 1.5 credit hour overload) is assigned to assist with site visits and exit interviews. Additionally, the program has funded a student to assist the faculty member directing the internship with the managerial details of host site list upkeep, office and paper work, data entry, and management of documents. In looking back, these adjustments seem to have addressed the shear sense of being overwhelmed in processing close to 150 students annually through the internship program.

At Youngstown State University, each student is assigned a faculty supervisor that along with their teaching responsibility monitors the overall experience of the interns, with the prime mode of communication being via email correspondence. From prior discussions on previous 
topics regarding Youngstown State University, the program director also carries out duties pertaining to the qualifications of the students to enter the internship. In effect, they have multiple people completing multiple tasks within the internship program, in lieu of one person comprehensively completing the duties. Given the size of the program, Dordt College maintains a one-person show - in that, in addition to a regular teaching load, one faculty does all tasks related to the internship experience.

\section{Student-Site fit}

One of the more engaging round table discussions at the pre-workshop contained an emphasis on what happens when the "fit" is just not there between the placed student and the host site. This is not novel as Campbell and Kovar (1994) remind us that sometimes interns are not adequately prepared to work well in the environment in which they are placed. More recently Hebert, Wood, Jenkins, and Robison (2017) addressed difficult situations with student and placement site fit. They acknowledged that while most unfortunate situations do not materialize due to the front-end work programs do (i.e., establish pre-requisite classes, require grade point average minimums, and hold orientation sessions about the internship) challenges may emerge between a student and a site. Finally, Paternostro-Bayles (2009) reflects on the "unique challenge" related to giving students different hands on learning experiences; particularly in less defined programs of study.

What became clear early in the pre-workshop discussion is that there are some subdisciplines, by nature, that are well defined in the expectations of a student during the internship program. Physical education pedagogy comes to mind. Teacher preparation tends to be defined at the national and state level, with evidence of this found in the standardized tests for both entry into a program and exit into licensure and certification. Therefore, the alignment between a 
student and a site tends to be closer regarding scope of work and the related expectations. That is not to say there are no issues with a student teaching internship. Clearly, there can be, but the point is that the expectations of the student intern and the host site tend to be naturally affiliated closely given the more traditional teacher training found within colleges and universities.

However, some sub-disciplines are not as clearly defined when it comes to both program preparation outcomes and possible employment opportunities. As a result, the true focus and passion of the student may not be revealed or as clear as it is for the student entering teaching. This can be found in the general exercise science major or even the sport management major. In both majors there are vast opportunities for employment and being able to gauge the student aptitude, interest, and disposition toward a specific industry much less placement-site is heightened. IUPUI addresses this topic in two ways; first, the unit highlights how one of our programs approaches internship pre-requisite courses, the engagement in a pre-internship course, and providing an alternative internship to greatly reduce, if not eliminate, any "fit" or preparation issues that may arise. Second, administrators discuss what they can do in the event the lack of fit cannot be successfully addressed.

In trying to reduce, if not fully prevent the lack of fit issue, IUPUI has found that there are a few preventative steps one can take. First, one could identify a set of courses which would serve as a pre-requisite to the internship and attach a minimum grade to those. By having a common set of courses with a threshold performance level, a program will be able to screen each pre-intern student. What tends to result is that students will end up screening themselves and stratifying their commitment to the program as demonstrated by their grades. This allows the program to better understand each internship candidate's strengths and weaknesses which may be predictive of future internship fit. 
Even more rigorously, Youngstown State requires all, but one course be completed prior to the student entering the Internship. This is even more compelling of a case for pre-emptive steps to ensure internship readiness, as among the three of us, our colleague at Youngstown State University reports the least number of situations that can be deemed as a "poor fit".

Second, the student could be required to apply for the internship and while the application could include courses and grades, it could also prompt the student to respond to questions in hopes of informing the internship faculty on the best fit possible or conversely the least ideal fit. For example, Youngstown State employs a series of "quizzes" the student must complete prior to receiving approval to register for the internship. The first quiz asks questions that prompt students to articulate their dream job, what populations they are and are not interested in, their ideal work day, etc., which will hopefully remove most doubt on what type of placement site would be best positioned to support the student. If a program can better understand a student whose dream is to work with adults with disability, for instance, they can work hard at finding a site that will prepare and equip that student with the necessary skills, knowledge, and disposition to make that next step manageable.

At IUPUI, a third safeguard was added. The unit developed a two-tiered internship program. Basically, in the semester prior to the external internship, the student must take an internal internship course. This 3-credit hour course is considered as on on-campus, in-house internship. There are two noteworthy elements of this course. First, there are a set of prerequisite courses to ensure base skills and knowledge by the student. Second, the students work with campus employees under direct faculty supervision in a relatively controlled setting as a personal trainer to not only refine their knowledge, skills, and competencies but at a level deemed acceptable for the upcoming external placement site. The internal internship also allows 
the student a real-life experience to better assess their own proficiencies and deficiencies to line up their attributes to the external internship site for an improved fit at the final stage of their academic career. It also fortifies how ready the student is for an internship and what type of placement they should engage in for their external internship so that that they may best learn and grow.

So, what happens when it becomes clear the internship experience is not mutually beneficial? Based on the discourse, having a worst-case scenario plan in place is in everyone's best interest. This is the one area where many of us agree. During the pre-workshop and then within conversations in preparation of this article, it appears each of us intervenes early and often when we hear of a possible concern from the host site. Moreover, based on isolated discussions with both the student and the site, our first goal is to try to recalibrate each stakeholder's expectation and offer interventions that would allow the placement to continue. The interventions could be in the form of professional development for the student, outside of the internship, to freshen up student skills (hard or soft) that may be causing this rift. Or, it could be engaging in more communication with the host site and university supervisor to ensure a sense of professionalism is being displayed and developed by the intern. Finally, more in-person visits at the site of the intern could be enacted and then followed with debriefings of the triad that makes up the internship experience (student, host, and faculty). Regardless, we remind everyone involved that the internship is a class, as part of the curriculum, and that learning should take place. All these programs highlight that student flawlessness is not a realistic expectation to hold; and for that matter, that should not be the expectation of the host site either.

Our perspective here is that very little in life is perfect. More importantly, there are lessons in everything we do, and it is not a good practice to quit if things start out with difficulty. 
Thankfully, most of the time these interventions prove successful and the internship continues. We all note the lessons to reduce the chance of this occurring in the future. In the rare event that there is not a solution in sight or one of the parties is adamant against the intern continuing, the options we have are to offer an incomplete and start a re-placement process. In fact, at IUPUI, given the scale of its internship program, over the years the internship director has developed a small set of host sites that are "on hold" in the rare event there is a need to get a student re-placed quickly. Youngstown State also has developed good relationships with certain sites that are willing to work with students that need to be re-placed. In these regards, provided the student did not behave unethically, criminally, or unprofessionally we can call upon those sites to see about an immediate placement to, ideally, avoid a delayed graduation. However, if the student was the prime reason of the discord, then the options of an incomplete or failure are initiated as necessary.

Alternately, IUPUI has recently developed a rather innovative approach to ensure a good fit. This is a research-based internship. In this format a student (intern) enrolls in a permissiononly section of the typical internship course and instead of being placed within an organization outside of the campus for the typical immersion experience, they are placed with a research faculty member on the campus. The internship coordinator is not the instructor of record, rather a separate faculty member takes on this role. As such they teach the section and oversee various semester long research projects derived in the course. This approach is new within higher education and was first reported on in the discipline of nursing (O’Brien \& Hathaway, 2018). The course is focused on developing mastery in the knowledge, skills, and dispositions of the research process which, ideally, prepare students for the rigors and characteristics of the principles of graduate and professional learning. The compelling thought focused on the reality a 
certain portion of IUPUI exercise science majors were in fact pursuing a graduate or professional degree immediately after graduation. At the same time, administrators noticed the internship placement sites were based on helping students use their degree as a terminal degree. As such, the placement site was expecting an intern who had their sights on employment upon completion of the internship. However, the reality was that some of the majors intended to pursue graduate or professional school upon graduation. This created misalignment among all elements of the intern and placement site dynamic, which included: professional disposition, feedback, area of interest, etc. This was not fair to the placement site or the intern.

A placement site should have an expectation that the intern is fully engaged in becoming the best employee possible and learning about professionalism. Yet, the intern should have the expectation that the internship would be meaningful and supportive of their academic goals. IUPUI faculty developed an internship, with goals, objectives, and outcomes aligned to graduate and professional programs and realized that a formal undergraduate research internship could accomplish all of these. As of now, this 2.5-year-old research-based internship alternative has met the enrollment maximum each semester, with one or two semesters achieving a wait list above the planned enrollment cap.

\section{Assessing the internship}

One of the elements that tends to be either overlooked or briefly attended to is assessment of the internship experience. The reality for faculty tasked with coordinating the internship process is that the process is truly cyclical. There is never a down time as one is either orienting an upcoming cohort of interns, visiting and communicating with current interns, or processing the paperwork and summaries of recently finished interns. This is in addition to a faculty 
member's teaching load, campus service expectations, and research or scholarship expectations. This may contribute to the sidelining of thorough assessment of the internship program.

Templeton, Updike, and Bennett (2012) pose another thought regarding the purpose of assessing student learning via the internship. The essence of their conversation centered on the goal of an internship; is it the process or the product that should be the assessment focus? It can be argued that the internship is still a learning opportunity and student growth over the internship placement should be the predominant way to assess student learning; this represents process. However, some argue the internship, as a capstone course, should reveal the preparation of the student and assessment should be about finding out the extent to which a student demonstrated mastery of the program outcomes; this represents product. Regardless of where one lands on the process versus product continuum, it appears assessment is acknowledged as an ideal way to ensure the internship is doing what it is purported to do along with providing the very necessary and vital feedback to the intern about one's performance. This reinforces the earlier work of Wolf (1993) who suggested that not having clear goals (such as, process vs product) leads to assessment that most likely is not very useful.

At IUPUI, Youngstown State University, and Dordt College the internship is guided by learning outcomes. While they are constructed differently, we are each in agreement on the significance of establishing learning outcomes for the internship. As a result, once the student learning outcomes for an internship are identified then assessment inevitably follows. Outcome assessment may be measured indirectly or directly. Indirectly assessing outcomes may be in the form of student reflection, student or site supervisor survey, or exit interviews. Direct assessment requires a demonstration of the student's work which reflects more tangible outcomes typically in the forms of rubrics, exams, or presentations, etc. 
Bulger (2006) acknowledges that within kinesiology internships, there is a challenge of providing meaningful feedback for an intern. Having an assessment plan in place is significantly beneficial to the student and worth the effort to put systematic assessment into place. Bulger (2006) also notes that most internships use only a single method of assessment.

From the discussion at the pre-workshop the most popular assessment was a site survey in a summative sense. Gibala and Stuhldreher (2001) supports this and suggests assessment via a survey is popular, yet the question becomes what kind of survey and for what reason? Within kinesiology, based on the internship requirements a survey would have to be all encompassing so that it can be used to verify hours accomplished, professional disposition, competence, and growth and learning. Perhaps even questions mapped to program outcomes could be included.

In addition, Toohey, Ryan, and Hughes (2006) identified five early ways to assess internships in kinesiology. They include assessing on attendance, assessing based on work history, assessing based on ability, assessing using a competency model, and finally, kinesiology internships were assessed and evaluated using a negotiated curriculum. Negotiated curriculum is one that can help the faculty liaison better understand issues or concerns and do so in a timelier fashion. This is the only form that is not solely controlled by the on-site mentor.

Campbell and Kovar (1994) supports this reframing of assessment source by encouraging the use of self-reflection journaling to sharpen an intern's critical thinking skill. In this way the student will be better prepared to complete any associated exit interviews or self-reflections that is expected in the program while also demonstrating personal growth as a reflective practitioner; which emulates the key elements of the HIPs that have been discussed previously.

\section{Conclusion}


We have summarized a few of the many meaningful discussions from the 2018 AKA pre-workshop on internships in kinesiology. While we shared many "best practices", the authors suggest that what is a best practice for one institution may not be a best practice for another institution. Location, program size, budgeting model, academic home, sub-discipline objectives and outcomes, and various faculty workload and academic policies, clearly, are determinants to how an internship program is built and maintained. What we can agree upon is how vital an internship is for students as they move through our programs. We did this by reinforcing the establishment of an internship as a HIP; provided it contains the needed elements.

We invite continued discussion about the elastic nature of internships within kinesiology that make one set of best practices nearly impossible to define or even agree upon. As an industry, maybe it would be a better choice to try and develop "tiers" of best practices for internships that could inform not only different institutions but even the different sub-disciplines of kinesiology. And the tiers of good, better, and best practices may be of benefit to the programs who have offered internships for a long time and to the programs who are new or still contemplating the adoption of an internship program. We believe strongly that the AKA would be a great place to help develop and host a clearinghouse of varied best practices. 


\section{Reference list}

Bulger, S. M. (2006). Maintaining connections: A web-enhanced approach to undergraduate internship supervision. The Physical Educator, 63(6), 114-125.

Campbell, K., \& Kovar, S. K. (1994). Fitness/Exercise science internships: How to ensure success. Journal of Physical Education, Recreation and Dance, 65(2), 69-72.

Gardner, P. (2013). Framing internships from an employers' perspective: Length, number, and relevancy; Collegiate Employment Research Institute (CERI). Retrieved from http:/www.ceri.msu.edu/wp-content/uploads/2010/01/internshipCERI-Research-Brief$\underline{\text { XX.pdf }}$

Gibala, D., \& Stuhldreher, W. (2001). The internship as a capstone experience: The bridge from academia to practice. Quarterly Bulletin of the Council on Linkages between Academia and Public Health Practices, 15(2), 2-7. Retrieved from http://www.phf.org/Link/vol15 n2/internship.pdf

Hebert, E., Wood, R., Jenkins, J.M., \& Robison, C.E. (2017). Internship management, placement, and on-site visits in kinesiology. Kinesiology Review, 6(4), 394-401. doi:10.1123/kr.2017-0042

Howard, J. (2001). Service-learning course design workbook. Ann Arbor, MI: OCSL Press.

Kuh, G., O’Donnell, K., \& Schneider, C. G. (2017). HIPs at ten. Change: The magazine of Higher Learning, 49(5), 8-16. doi:10.1080/00091383.2017.1366805

Labaree, D.F. (2008). An uneasy relationship: The history of teacher education in the university. In M. Cochran-Smith, S. Feiman-Nemser, J. D. McIntyre, \& K. E. Demers (Eds.), Handbook of Research on Teacher Education: Enduring questions in changing contexts (pp. 290-306). New York, NY: Routledge. doi: 10.1111/j.1467-873X.2008.00421.x 
Morrisey, J. I., Beckett, J. A., Sherman, R., \& Leininger, L. J. (2017). Establishing partnerships for effective academic programs. Kinesiology Review, 6(4), 384-390. doi:10.1123/kr.2017-0040

Murray, M. A., Zakrajsek, R. A., \& Gearity, B. T. (2013). Developing effective internships in strength and conditioning: A community of practice approach. Strength and Conditioning Journal, 36(1), 35-40.

National Association of Colleges and Employers. (2013). Job outlook 2013 spring update. NACE. Retrieved from https://www.roanestate.edu/webfolders/HARRISB/placement/articles/staff/Job_Outlook 2013-Spring_Update.pdf

Paternostro-Bayles. (2009). Maximizing your professional preparation: Through clinical exercise physiology and health fitness internships. ACSM's Health \& Fitness Journal, 13(2), 35-36.

O’Brien, T. \& Hathaway, D. (2018). Students and faculty perceptions of an undergraduate nursing research internship program. Nurse Educator, 43(2), E1-E4. doi: 10.1097/NNE.00000000000000412

Rinsch, E. (1966). The history of the Normal College of the American Gymnastics Union of Indiana University, 1866-1966. Indianapolis, IN: B \& L Composition \& Printing. Ryan, P. (2005). IDEA fitness industry salary survey 2004. Fitness Journal, 2(5), 43-50.

Stack, K. \& Fede, J. (2017). Internships as a pedagogical approach to soft-skill development. NACE Journal, 78(1), 32-39.

Templeton, W., Updyke, K., \& Bennett Jr., R. B. (2012). Internships and the assessment of student learning. Business Education and Accreditation, 4(2), 27-38. 
Toohey, S., Ryan. G., \& Hughes, C. (2006). Assessing the practicum. Journal of Assessment and Evaluation in Higher Education, 21(3), 215-227. doi: 10.1080/0260293960210302

Wentz, D. K. \& Ford, C. V. (1984). A brief history of the internship. Journal of the American Medical Association, 252(24), 3390-3394.

Wolff, C., \& Svanum, S. (1976). A survey of APA-approved internship availability. Professional Psychologist, 6(3), 356-358.

Wolff, L. O. (1993, November). Assessment in the capstone course: Trial and error. Paper presented at the Annual Meeting of the Speech Communication Association, Miami Beach, FL. Retrieved from https://files.eric.ed.gov/fulltext/ED367002.pdf 
Table 1

Example of SLO's for Wellness Based Internships

Behavior modification

- Identify client's stage of motivational readiness and appropriate behavioral strategy for improving behavior change.

- Develop conflict resolution techniques to facilitate communication among clientele.

- Develop and provide educational resources to support clients in the adoption and maintenance of healthy lifestyle behaviors.

- Develop strategies to improve motivation such as client specific goal setting, incentive programs, social support, or recognizing one's achievements.

- Develop strategies to improve non-structured physical activity levels among clientele.

Exercise Prescription

- Demonstrate appropriate exercises for clients with appropriate modifications based on age, physical condition, and current health status.

- Develop and implement the FITT-VP principle for clients.

- Apply an appropriate energy cost, oxygen cost (VO2), and MET level of various activities to the client's exercise prescription.

- Develop strategies to incorporate teaching demonstrations regarding the use of a variety of cardiovascular exercise equipment.

- Determine each client's minimal threshold of physical activity required to achieve health benefits and/or fitness advances. 